\title{
Environmental Education, Environmental Ethics, and Environmental Perceptions of Food Establishment Employees in a Philippine University
}

\author{
Lea Ivy O. Manzanero \\ University of the Philippines
}

\begin{abstract}
The waste management challenge in university campuses includes food and food packaging materials. Being foremost affected by the food-related waste stream, 92 employees from food establishments located inside the University of the Philippines were provided expert-validated survey questionnaire to identify their perception on environment and pollution as well as describe their awareness on environmental education and environmental ethics concepts. Thirty-nine (42.4\%) related the concept of environment mainly to trees, plants, animals, and the physical environment such as rivers. Only twenty-six (28.3\%) expressed an attitude of concern on the current state of the environment. Six (6.5\%) conveyed negative human behavior as the reason why the environment is in a dismal state and the same percentage (6.5\%) showed concern for the environment mainly because humans benefit from it. Fifteen (16.3\%) opted not to share their opinion. For perception on pollution, thirty-six (39.1\%) linked the concept to the presence of land, air, or water pollution and twenty-three (25\%) associated the pollution to negative effects on human health and on the environment. Twelve (13\%) mentioned concern over the presence of pollution and twenty-one (22.8\%) did not share their opinion on pollution. Awareness on environmental ethics concepts was identified using 15-item Likert Scale Questionnaire. Areas in environmental concepts where participants most strongly agreed include "value of life," diversity and intrinsic value, cooperation, common good, and social responsibility. Results of this survey will be integrated into the discourse on the proposed policy of the University of the Philippines to segregate waste at-source. The said policy seeks to ensure that: (1) only food waste from concessionaires will be deposited directly to the compost site; (2) recyclables are to be sold; and (3) only residuals such as non-biodegradables and non-recyclables are to be sent to the dumpsite.
\end{abstract}

Keywords: food establishment, employees, environmental education, environmental ethics, Responsible Environmental Behavior (REB), pollution, environment, Solid Waste Management (SWM), university

\section{Background of the Study}

The World Bank's recent issue of the Philippine Environmental Monitor on Solid Waste (2001) depicts the Philippines' garbage crisis as one of the most pressing environmental concern. Metro Manila is characterized by declining water quality in river and coastal waters, and increasing solid and hazardous waste generation and improper waste management. Twenty-three percent of total waste generated in the Philippines comes from

Lea Ivy O. Manzanero, M.A., UP Program for Environmental Governance, Center for Integrative and Development Studies, University of the Philippines, Philippines; main research fields: Environmental Education and Ethics. 
Metro Manila with 10 million tons annual generation expected to rise $40 \%$ at the end of the decade (Philippines Environment Monitor, 2001). The Philippines Brown Environment Report (2005) mentioned about the composition of solid waste generated in the country. In Metro Manila, the National Solid Waste Management Commission reports that food/kitchen wastes account for about $45 \%$ of the total solid waste (estimated at 6,700 metric tons daily) generated in the area. Paper waste accounted for $16 \%$; plastic is about $15 \%$; glass and wood, 9\%; others 15\%. A USAID-assisted Philippine Environmental Governance (EcoGov) Project in 2003 had a study of solid waste generation in nine cities and 10 municipalities outside of Metro Manila in the Philippines. The study showed that more than $60 \%$ of the total solid waste generated by local government units or LGUs is biodegradable which meant that these could be composted while about $20 \%$ is recyclable and only $2 \%$ is comprised of special wastes.

The closing of landfills in Carmona, Cavite, and San Mateo, Rizal set off the garbage problems in Metro Manila. The annual expenditure of Metro Manila for garbage collection is Php 3.8 billion, approximately Php 1,500 (or about 34 USD) per ton of garbage amounting to Php 10.5 million per day. If recyclables and biodegradables are segregated at source and do not end up in dumpsites roughly, Php 3.61 billion will be saved equivalent to saving around 95\% in costs. Moreover, the ADB Review (2000) mentioned about the high risk activity and threat of dumpsites in the Philippines such as the avalanche of garbage in Payatas dumpsite in July 2000 where at least 200 people died.

The University of the Philippines is not exempted from this challenge. With a land area of 493 hectares and about 3,000-sq. meter lot used to house a shed for recyclables, a composting area and an area for vegetables, ornamental plants and some fruit trees and 10 collectors who go out everyday on their buggy carts around campus, managing solid wastes can be a difficult task. There is lack of empirical data about the extent of application of EE in food establishments that can pave the way for producing environmental literate employees that possess REB and environmental ethics.

\section{Approaches to Environmental Problem-Solving}

\subsection{Role of Environmental Education (EE)}

In order for EE to be meaningful, it must relate to real world situations (Rao and Reddy 1997). The Philippine Strategy for Sustainable Development promotes Environmental Education (EE) to encourage responsible environmental behavior of citizens, individuals, and social groups (Segovia and Galang 2002). EE aims to aid citizens in becoming environmentally knowledgeable, skilled, and dedicated citizens who are willing to work toward achieving and/or maintaining a dynamic equilibrium between quality of life and quality of environment (Hungerford, Peyton, and Wilke 1980). Experience in the natural world is an essential part of EE and gives opportunity to solve real environmental problems (Paehlke, editor, 1995).

Key characteristics of EE include first-hand experiences and activities that require commitment to the development and utilization of all situations where learning can be nurtured through first-hand experiences and activities which foster a deep respect and love for the natural world and active participation in preventing and solving environmental problems (Hart 1981). EE training can be an indispensable tool to contribute to environmental problem-solving. Nollen and Gaertner (1991) found out that employees' skill levels can be influenced by training and experience. 


\subsection{Responsible Environmental Behavior (REB)}

Sia, Hungerford, and Tomera (1985/1986) defined Responsible Environmental Behavior (REB) as a learned action/response. It also refers to the variety of recognized approaches to environmental action available to individuals or groups for use in preventing or resolving environmental problems or issues (Marcinkowski 1988). Sia et al. (1985/1986) suggested that in order to produce environmentally responsible citizen who can work for a balance between quality of life and quality of environment, it is important that these predictors of REB be addressed.

Hwang, Kim, and Jeong (2000) refer to these variables as "antecedents" of REB. These variables include level of environmental sensitivity, perceived knowledge of environmental action strategies, perceived skill in using environmental action strategies, psychological sex role classification, individual locus of control, group locus of control, and attitude toward pollution. A person's intention to act refers to a person's behavioral intention as a function of attitude toward the behavior and the subject norm (Penrod 1986) while environmental sensitivity refers to the set of attributes which results in an individual viewing the environment from an empathic perspective (Peterson 1982; Chawla 1998).

$\mathrm{EE}$ is a process that can guide the transition toward REB. EE is also an interdisciplinary approach to solve environmental problems in local context (EE Guide, 1999). With the poor environmental situation in the Philippines, EE can be tapped as a process that can help achieve REB of employees who are the key players in making environmental problem solving a success in relation solid waste generated by food establishments.

\subsection{Environmental Ethics}

Environmental problems arise from the wrong notion that the environment is a common property that can be dispensed with to attain development (Rigg 1995). This supports the anthropocentric worldview in which humans are seen as exempt and above the rest of nature (Geller and Lasley 1985/1986).

The Universal Declaration on Bioethics and Human Rights, adopted by UNESCO's 33rd General Conference, in 2005 considered:

Due regard is to be given to the interconnection between human beings and other forms of life, to the importance of appropriate access and utilization of biological and genetic resources, to respect for traditional knowledge and to the role of human beings in the protection of the environment, the biosphere and biodiversity. (UNESCO, 2005)

Environmental ethics includes ethical reflections on human interactions with the natural environment and is also concerned with the issue of responsible conduct with respect to natural landscapes, resources, species, and non-human organisms.

\section{Rationale}

The Philippines Presidential Decree 856 defined food establishments as establishments where food or drinking are manufactured, processed, stored, sold, or served. Health certificates are required by law and quality and protection of food must be guaranteed. This law also describes the physical characteristics of the food establishments such as the walls and ceilings, space requirement, and even food sanitation, handling, and safety. Its application in relation to environmental principles however is limited to disposal of refuse and does not discuss waste segregation until the passing of the Republic Act 9003 or the Ecological Solid Waste Management. 
In the Philippines, evaluation of food establishments falls under the jurisdiction of the provincial, municipal, or city health officers every six months. Failure to comply means revocation of license or suspension of operation. Food establishments inside the university contribute to solid wastes. However, right now, there is lack of empirical data about the extent of application of EE in food establishments that can pave the way for producing environmental literate employees that possess REB and environmental ethics. Without this, it is difficult to develop training and instructional approach to promote EE and REB.

The office of the Vice Chancellor for Community Affairs of the University of the Philippines (UP) Diliman upholds close relationship between the university and the residents in the Diliman community by continuously working for a safe, clean, orderly, and peaceful environment for the entire Diliman community. The Business Concessions Office (BCO) is the one responsible for the efficient collection of rentals and surcharges of business concessionaires in the University as well as updating of contracts of business operators in the University and the monitoring of their activities. Privately managed food and business outlets had fallen under the jurisdiction of BCO since September 1994 when Administrative Order No. 128 was issued by the Chancellor of UP Diliman. Both the office of the Vice Chancellor for Community Affairs and the food establishment owners and managers have the power to mould policies that can then promote environmental problem solving but they need the cooperation of employees in Solid Waste Management (SWM).

\section{Methods}

The study involves randomly selected employees in food establishments inside the UP Diliman campus which include but not limited to those on contractual status or rank and file. The perception of employees on the environment, EE, and pollution was examined that they were surveyed to answer the following questions:

(1). What is the perception on EE of employees in the food establishment?

(2). What is their perception on the environment and on pollution?

(3). What is the level of the employees' environmental ethics?

(4). What does specific environmental ethics concept predominate the employees’ perception?

\section{Data Collection Procedure}

Endorsement letter from the office of the Vice Chancellor for Community Affairs was granted to conduct the study among the food establishments inside UP Diliman campus. It assured the food establishment owners and supervisors that the questionnaire had been reviewed. Expert validated survey questionnaires were given and when the schedule of the employees permitted, such as during their break time or during lean period in operation, the proponent sat with them in a group as the employees answered the questionnaire and gave clarification on their questions regarding the survey. In some instances, the survey questions were left for them to answer and inquiries were answered thru SMS (text messages) and the survey was collected afterwards.

\section{Questionnaire Design}

Prior to the development of the Survey Tool in EE, Predictors of REB (Responsible Environmental Behavior) and Environmental Ethics, three technical experts from food science, two experts from environmental education, and an expert in bioethics were shown copy of the questionnaire for comments and suggestions. After inclusion of their comments and gaining their go signal, the survey was considered ready to use.

The following are the instruments used for this study: 
(1). Information Questionnaire - this researcher-made questionnaire provides demographic data covering employees name (optional), gender, age, number of years in the food establishment, educational attainment, and training on EE or pursuit of quality such as EMS (Environmental Management Systems) in the last 5 years.

(2). Questionnaire on Perception — this researcher-made questionnaire serves as self-assessment instrument on employees' understanding of EE, their concept of the environment, pollution, and quality.

(3). Questionnaire on Predictors of REB and Environmental Ethics-this researcher-made instrument is comprised of sets of questions that will determine employees' attitude, locus of control, intention to act on issues affecting the environment, and those that contribute to environmental problem solving and environmental ethics. This instrument on REB had been copyrighted in 2008 by the author and registered at the Philippine National Library while the instrument on Environmental Ethics had been formulated by adopting some concepts from the UN Declaration on Bioethics and Human Rights after the author attended the Workshop sponsored by UNESCO Bangkok and UP Diliman College of Social Sciences and Philosophy (CSSP).

The Questionnaire on Predictors of REB consisted of 15-item questions each for environmental attitude, locus of control (LOC), and intention to act in a responsible environmental manner. For environmental attitude, the 15 items focus on SWM, concept of quality or safety, resource conservation, and concern for the common good. The 15-item questions on LOC try to measure whether the employees believe that they have the capacity to contribute change thereby indicating a high internal LOC. Items that show external LOC on the other hand used institutions to initiate change such as schools, NGO, government agencies, media, and even application of science and technology. For the items on intention to act in a responsible environmental manner, items focus on SWM, concern for the environment, and pursuit of quality or safety. Items on environmental ethics look at how the respondents consider common good, cooperation, social responsibility, value of life, diversity, and social responsibility. The data presented on this paper however focus only on Environmental Ethics and perception on environment and pollution.

The pilot study included 37 employees of food establishments inside UP Diliman campus and was conducted for the entire month of September 2009. The Survey Questionnaires were approved after consultation with panelists and validated by the proponent's colleagues in food science and food service. The Filipino version was used to make it easier for the respondents to understand. However for ease of discussion, the English version was used for the presentation and discussion of this study. Questionnaires on Environmental Ethics were answered using Likert Scale ranging from Strongly Agree to Strongly Disagree and were given numeric count of 1 to 5 .

To provide a unique estimate of the internal consistency or reliability for a given test, Cronbach's alpha requires only a single test administration (Gleim and Gleim 2003). The minimum alpha used in this is study 0.70 which means that the item included in the set of questionnaire is acceptable while 0.90 is excellent and 0.80 is good.

The research participants are 92 (53 females, 27 males, and 12 unidentified respondents) employees of food establishments within UP Diliman campus. Food establishments include those in CASAA, Beach House, CS, Math Building, NISMED, Law, CSSP, Engineering, Mass Communication, Music, NCPAG, Vargas Museum, and in dormitories such as Kalayaan Residence, Ilang-ilang Residence Hall, and Molave. The main factor influencing choice of participants is their willingness to participate in the study and the consent of the owner or supervisor managing the food establishment. Part of the assumption for this study is treating the 
samples as homogenous since the participants and the owners and supervisors do not want their food establishment to be identified or singled out once the results are analyzed.

The employees' lengths of stay in the food establishments vary from less than one year to more than ten years of service and are either involved in cooking and food preparation and handling/serving and performing kitchen operations. Their length of stay breeds familiarity of the daily operations in the food establishments which may have direct or indirect impact on the environment. However, one limitation of this study is that it does not include how often employees are replaced if they are in contractual basis or how long a regular employee usually stays employed in the food establishment.

\section{Results and Discussion}

\subsection{Background of the Food Establishment/Company}

Informal and unstructured interview was done with the owner or supervisor of food establishments in UP campus and was found out that there is no existing environmental education policy. The only food establishment which allowed interview was NISMED, NCPAG, Vargas Museum Café, Beach House, and Math Building. Common to these establishments is the response that EE in not explicitly mentions in their policy but stresses that they practice SWM and anti-smoking policy. Maintaining cleanliness at all times is the most direct application of EE in the food establishment.

One food establishment owner mentioned that the absence of organization of food establishment owners makes it hard for them to discuss issues affecting their business within the university. The responses of the food establishment owners or supervisors were similar to the responses of their employees in their survey.

Eighty-eight percent (81 out of 92) of the respondents mention that environmental protection is part of their company's mission and relate it to SWM. However, 83.5\% (76 out of 92) of the respondents agree that EE is integrated or is a part of the food establishment's mission even though the owners or supervisors state that EE is not specifically written in their Mission/Vision Statement. 89.1\% (82 out of 92) of them believe that the establishment has an overall environmental policy. $89 \%$ believe that environmental consideration is a criterion for decision-making in their establishment such as implementing SWM and majority of them (97.8\%) agree that there is a person assigned for environmental projects or programs. 87.9\% agree that personnel are required to practice environment-oriented activities. However, only $79.8 \%$ believe that their establishment has a purchasing policy that rejects products which are harmful to the environment.

\section{Table 1}

\section{Respondents' Perception on EE}

\begin{tabular}{ll}
\hline Food Employees' Responses Related to EE & Percentage \\
\hline Environmental protection as part of company’s mission & $88 \%$ \\
EE is integrated in company's mission & $83.5 \%$ \\
Belief that that food establishment has environmental policy (specifically on SWM) & $89.1 \%$ \\
Belief that it is important to consider the environment in company policy & $89 \%$ \\
There is a person assigned to perform environmentally related to activity such as SWM & $97.8 \%$ \\
Belief that employees should be involved in environmental programs & $87.9 \%$ \\
Purchasing power & $79.8 \%$ \\
\hline
\end{tabular}




\section{Table 2}

\section{Respondents' Response on Environmental Programs and Practices}

\begin{tabular}{ll}
\hline Food Employees' Responses Related to Environmental Program and Practices & Percentage \\
\hline Solid Waste Management in the establishment & $93.3 \%$ \\
Smoke belching and smoking not allowed in establishment and inside campus & $86.8 \%$ \\
There is environmental project within UP & $97.8 \%$ \\
\hline
\end{tabular}

When the respondents were asked regarding an existing policy in the food establishments that they were working with, they were very clear about waste segregation, indicated by $93.3 \%$ but $97.8 \%$ of them indicated that there was no policy on the environment implemented within the university.

There is no policy yet inside the university to deal with plastic and most of the wastes which go to landfills come from plastics. Plastics are inexpensive, lightweight, and durable materials and have wide range of applications. As a consequence, the production of plastics has increased markedly over the last 60 years. A lot of disposable items of packaging or other short-lived products produced each year are made up of plastic which are discarded within a year of manufacture. About $50 \%$ of plastic is used for single-use disposable applications, such as packaging, agricultural films, and disposable consumer items (Hopewell et al. 2009). It is an indicator that current use of plastics is not sustainable. Usage of plastic is increasing and annual production is likely to exceed 300 million tons by 2010 (Thompson et al. 2009).

Lots of discarded end-of-life plastics are accumulating as debris in landfills and in natural habitats worldwide. Barnes et al. (2009) mentioned that the longevity of plastic is estimated to be hundreds to thousands of years, but is likely to be far longer in deep sea and non-surface polar environments. Another issue associated with plastic involves the leaching of chemicals from plastic products and the potential for plastics to transfer chemicals to wildlife and humans (Thompson et al. 2009). Barnes et al. (2009) also added that plastic debris poses considerable threat by distributing non-native and potentially harmful organisms and degrading to micro-plastics that may subsequently be ingested and the environmental consequences of such microscopic debris are still poorly understood.

Around $4 \%$ of the world oil and gas production, a non renewable resource, is used as feedstock for plastics and a further $3-4 \%$ is expended to provide energy for their manufacture (Hopewell et al 2009). Given our declining reserves of fossil fuels and finite capacity for disposal of waste to landfill, this linear use of hydrocarbons, via packaging, and other short-lived applications of plastic is simply not sustainable and having a clear policy to address usage of plastics inside the university can still have an impact on its demand.

Another issue related to pollution is the concept of post-consumer food waste which accounts for the greatest losses (Parfitt et al. 2010). Although their research describes it as occurring in affluent countries, food wastage also occurs inside the university either as food losses or food spoilage. Food waste is a waste of energy and resources put into all the process of farming, harvesting, processing, packaging, storage, transportation, distribution, and retail until it reaches the final consumer and the challenge in behavioral change to reduce post-consumer waste lies with the individual. The Filipino word "sayang" connotes a feeling of "too bad to be wasted" and can be used as a behavioral stimulus in EE training to address pollution by reducing waste at source and can be replaced with the Filipino concept of "sapat" meaning "just enough.”

\subsection{Environmental Education in the Workplace}

Of the 92 respondents, 58.4\% admitted that they did not attend formal EE training in the last 5 years and 
54.5\% also did not get any training on Environmental Management System (EMS) and Pollution Control. It is evident from the survey that EE training is not a part of requirement to work in a food establishment which generates solid wastes.

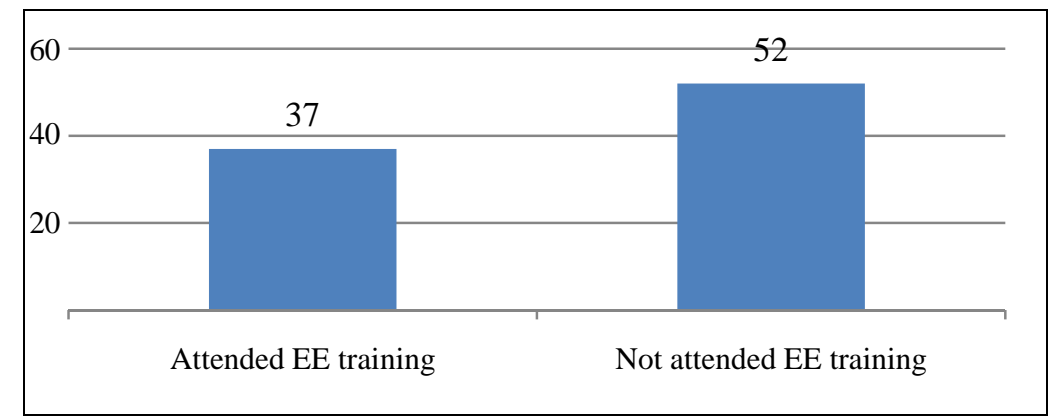

Fig. 1. Respondents who had training on EE.

There is also no policy yet in the university which promotes EE. It is the same situation described by Sia, Hungerford, and Tomera (1985/1986) where skills-training for citizen participation has not been given much attention and there has been paucity of data available to help in the understanding, predicting, and modifying of environmental problem-solving behavior. Moreover, there is lack of knowledge of factors that have formative effects on the development of environmentally responsible behavior (Hines et al. 1986). Fryman et al. (1982) as cited in Culen et al. (1986) mention that very few studies have actually been conducted regarding environmental behavior and environmental perception. While these authors focus on the formal education set up, study on EE and REB of other stakeholders of the environment like the ones in the business sector such as food establishments has been lacking.

Development of an environmental accountability among the citizenry can pave the way for the solution of these problems. This accountability can be fostered through Environmental Education whereby the development of positive attitudes and the acquisition of knowledge toward and about the environment can be developed (Jaus 1984). Generating substantial interest in critical issues is suggested by Culen et al. (1986) and would seem to be an efficient mechanism for improving citizen's responses. Klingler (1980) and Ramsey et al. (1981) as cited in Culen et al. (1986) indicate that learners given training in citizenship environmental action skills will tend to take action themselves and providing the employees with necessary training may strengthen their role in environmental problem-solving.

The most common tasks performed in the food establishment which has environmental implications include Waste Treatment, Storage and Disposal performed thrice a week by $57.8 \%$ of the respondents followed by Safety (57.3\%), Energy and Resource Conservation (53.9\%), and Recycling (42.7\%).

\subsection{Perception}

\subsubsection{On Environment}

Thirty-nine or $42.4 \%$ of the respondents relate the concept of environment to the presence of plants, trees, animals, and the physical environment such as rivers and mountains. $28.3 \%$ or 26 exhibit concern for the current state of the environment which looks positive since this aspect can be maximized in designing EE training for employees in the future. Most training focusing on environmental knowledge and focusing on environmental attitude, values, and ethics is another aspect which EE trainers can tap to foster REB. 
Six respondents or $6.5 \%$ have negative view of the environment stating that humans are partly to blame for the dismal state of our environment. Another 6.5\% (6 respondents) show concern for the environment because humans benefit from it. $16.3 \%$ or 15 respondents opt not to share their perception on the environment.

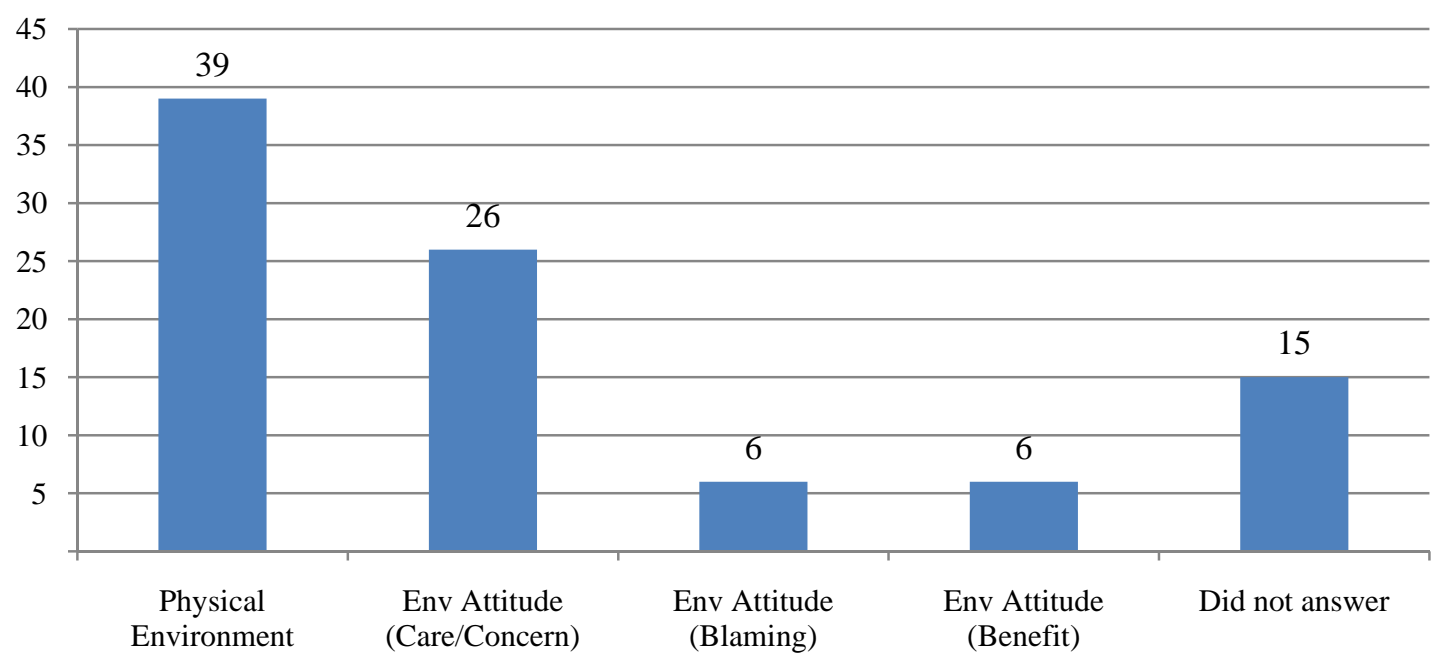

Fig. 2. Respondents' perception on the concept of environment.

\subsubsection{On Pollution}

In relation to pollution, $39.1 \%$ or 36 respondents relate it to either land, air, or water pollution and $25 \%$ or 23 respondents harbor negative feelings on pollution such as causing health problems. Twelve respondents (13\%) mention concern over the presence of pollution and 21 or $22.8 \%$ do not share their opinion.

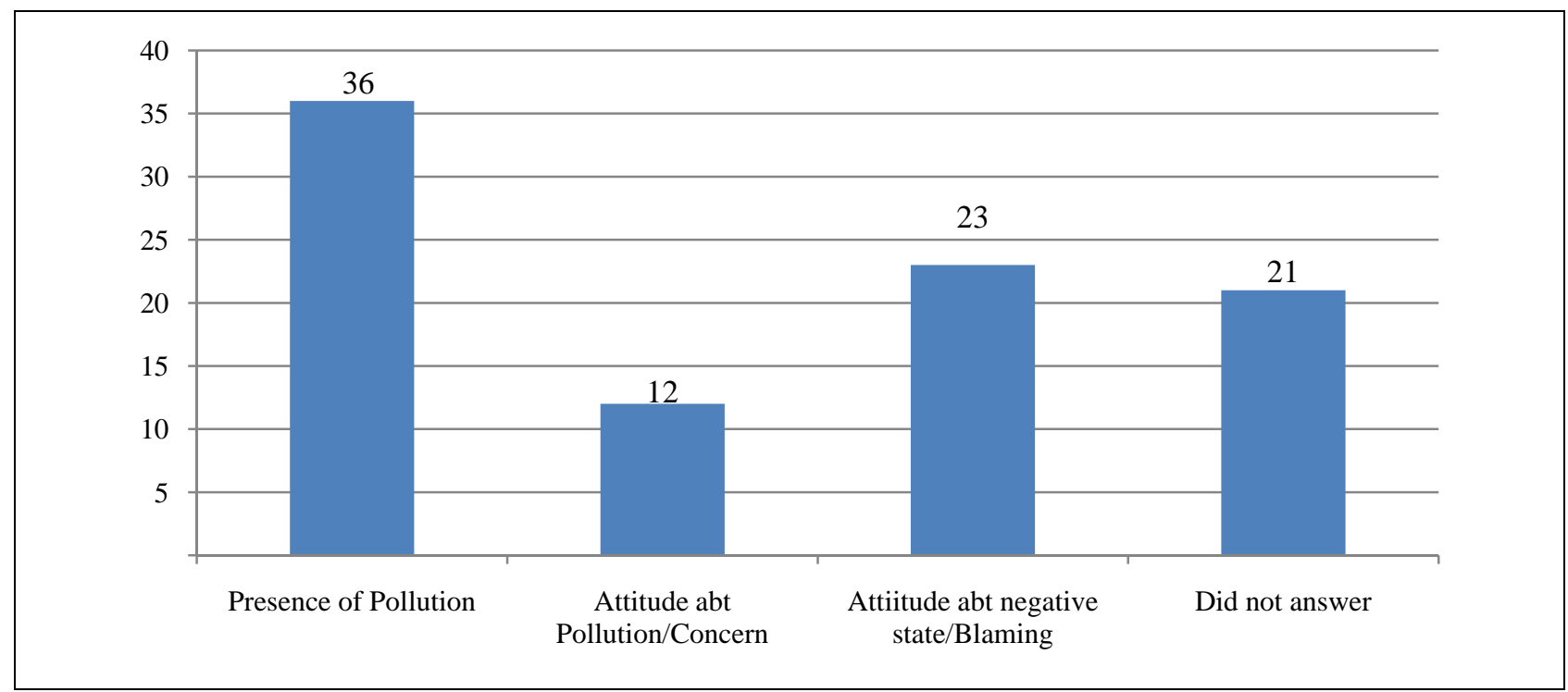

Fig. 3. Respondents' view on pollution.

The waste by the food establishment is really a cause of concern for the administration of the university since previous study done by ADB (2003) on Municipal Solid Waste Production in the Philippines (1999) show 
that it is mainly composed of kitchen waste (42\%). Paper waste follows by $19 \%$ then plastic composing $17 \%$ of municipal wastes while metal is only $6 \%$, garden wastes by $7 \%$ and other forms of waste comprise $9 \%$ (Parayno and Busmente, n.d.). Over Php 3.54 billion (64 million USD) is spent annually on the collection and disposal.

A lot of money is being spent on managing solid wastes. Metro Manila's solid waste costs about Php 1,450.00 (26.40 USD) per ton. Parayno and Busmente (n.d.) mention that local government expenses in Metro Manila for solid waste management are spent on private hauling contracts. Under the Local Government Code of the Philippines, local government units (LGUs) are mandated to collect fees for services. One of these is the collection of waste management fees from businesses, where the charges are incorporated in the annual application for business permits.

Although local government units are allowed to adjust fees every 5 years, most have not. Rates remain unrealistically low. For example, a typical fast food restaurant in one city pays only Php17 or roughly about 0.39 USD per day for waste disposal which is far below the actual cost. Collection of waste management fees at the household level is being implemented only in a handful of wealthier barangays, but overall the willingness of households to pay is limited. As for the University of the Philippines, there is no fee collected from establishments for collection of wastes.

Even though presence of pollution is the first thing that comes to the mind of the respondents, some of their actions on solid waste show otherwise. Visits from some food establishments show that they mostly segregate only the recyclables since they can sell it. Soda cans sell for Php 40 (0.90 USD) while PET bottles sell for Php 30 (0.70 USD) per kilogram. All disposable plastic cup and utensils, caps of PET bottles and plastic container or oil, and soy sauce sell for Php 10 (0.20 USD). Food wastes are collected by pet owners or as food for pigs by certain individuals while other food containers and plastics are thrown in the recovery facility. Recent visits from the garbage disposing area inside the university show that wastes are still not segregated and left for some kids and pickers to explore to find recyclables that they can sell.

\subsubsection{Environmental Ethics}

Initially, the questionnaire on Environmental Ethics has 15 items and has Cronbach’s Alpha of 0.665.

\section{Table 3}

Initial Reliability Test for Environmental Ethics Questionnaire

\begin{tabular}{|c|c|c|c|c|}
\hline \multicolumn{5}{|c|}{ Case Processing Summary } \\
\hline & & $\mathrm{N}$ & & $\%$ \\
\hline \multirow{3}{*}{ Cases } & Valid & 29 & & 78.4 \\
\hline & Excluded $^{\mathrm{a}}$ & 8 & & 21.6 \\
\hline & Total & 37 & & 100.0 \\
\hline \multicolumn{5}{|c|}{ a. Listwise deletion based on all variables in the procedure. } \\
\hline \multicolumn{5}{|c|}{ Reliability Statistics } \\
\hline \multicolumn{2}{|c|}{ Cronbach’s Alpha } & & \multicolumn{2}{|l|}{$\mathrm{N}$ of Items } \\
\hline \multicolumn{2}{|l|}{.665} & & \multicolumn{2}{|l|}{15} \\
\hline
\end{tabular}

Reliability was established for the questionnaire on Environmental Ethics at Cronbach's Alpha 0.723 after removing Questions Numbers 12 and 15. 


\section{Table 4}

\section{Reliability Test for Environmental Ethics after Removing Some Questions}

\begin{tabular}{|c|c|c|c|c|}
\hline \multicolumn{5}{|c|}{ Case Processing Summary } \\
\hline & & $\mathrm{N}$ & & $\%$ \\
\hline \multirow{3}{*}{ Cases } & Valid & 31 & & 83.8 \\
\hline & Excluded $^{\mathrm{a}}$ & 6 & & 16.2 \\
\hline & Total & 37 & & 100.0 \\
\hline \multicolumn{5}{|c|}{ a. Listwise deletion based on all variables in the procedure. } \\
\hline \multicolumn{5}{|c|}{ Reliability Statistics } \\
\hline \multicolumn{2}{|l|}{ Cronbach’s Alpha } & \multicolumn{3}{|c|}{$\mathrm{N}$ of Items } \\
\hline \multicolumn{2}{|l|}{.723} & \multicolumn{2}{|r|}{13} & \\
\hline
\end{tabular}

Environmental problems are made by humans because they lack environmental ethics (Vinai 2003; Wongchantra et al. 2008). Solutions in environmental problems do not lie in traditional technological approaches but in the alteration of human behavior (Maloney and Ward 1973; Culen et al. 1986). However, Environmental Education must not only seek out ways to develop and promote positive environmental behavior but should foster environmental ethics among humans.

Ethics is often described as a moral philosophy prescribing what is right and what is wrong. Ethics is the basis of society and desired social behavior. Prescriptive ethics states how the world ought to be rather than describing how it is. Environmental ethics can prescribe what is right because it is good for the environment, which means that it is good for the earth and for creation (Suliana Siwatibau 2008). Moral norms are able to govern human actions towards the natural world (Des Jardins 2001).

The level of Environmental Ethics of respondents in this study is high with mean of 1.87 in a scale of 1 to 5, 1 being the highest. The items on Environmental Ethics which has the highest means include:

- “All life forms are valuable" mean of 1.46;

- "It is my responsibility to take care of the environment, the biodiversity and the biosphere" mean of 1.58;

- "Nature has its own intrinsic value regardless of how humans benefit from it" mean of 1.64;

- "Schools and government institutions play important role in shaping responsible environmental behavior of people" mean of 1.65;

- "Cooperation is important in implementing environmental projects" mean of 1.67.

- Other items which got high level of agreement among the respondents are:

- "Caring for the environment will benefit future generations."

- "Transparency and accountability of the government and private companies regarding policies and projects which affect the environment is important."

From the survey, value of life is the main concern while responsibility of taking care of the environment ranks second in terms of the employees environmental ethics. Although for now, their main reason of separating the recyclables is to generate income, hence deals more on their benefits, it can be a start off point for training them in other environmental ethics concepts. In relation to common good and social responsibility, the respondents also recognize the role of institutions in shaping responsible behavior. This is another area where the university administration can look into to tap food establishment employees as allies in SWM.

Majority of respondents (92.3\%) believe in the importance of cooperation with others and also with cooperation with schools and government sector to promote predictors or responsible environmental behavior 
(91.2\%). This can be enhanced by establishing an association which owners or managers of food establishments participate into.

In relation to the concept of common good, about $89.1 \%$ of respondents show concern for future generations and $88.9 \%$ believe in benefit sharing, which are also concepts mentioned in sustainable development.

In relation to social responsibility, majority of respondents $(91.2 \%)$ believe that there should be transparency and accountability on the side of the government and companies on matters relating to the environment while $83.9 \%$ believe in the application of risk assessment and precautionary principle.

\section{Summary}

Food and drinks contribute to solid wastes together with their packaging materials and waste management is a challenging task to be left on the university administration alone to perform. Food establishments generally contribute to solid wastes inside the university.

Aside from the conventional way if implementing policy, some approaches which can be considered include environmental education training, enhancing REB, and environmental ethics application. $28.3 \%$ of the respondents exhibit concern for the current state of the environment and represent an opportunity to maximize their involvement in future EE training. It is important to note that many related literature about environmental education focuses on formal education contexts. Although attempts have been made to include all types of environmental education, its most widely application is in formal settings and how to make its context specific depends upon varying cultural understandings and interactions with the natural environment such as the case on solid waste management inside the university presented here.

In this context, we can say that the ultimate aim of environmental education "is to enable people to understand the complexities of the environment and the need for nations to adapt their activities and pursue their development in ways which are harmonious with the environment” (UNESCO and UNEP, 1978, 12). With $42.7 \%$ of the food establishment, employees' task related to the environment and their participating on recycling and segregating the recyclables for added income does not guarantee immediate success as shown in observations of still dumping of wastes in some areas inside the university.

Environmental ethics is a foundation for the existing Environmental Education (EE) and Education for Sustainable Development (ESD) programs, but not always well recognized or analyzed. EE/ESD deals with environmental problems while Environmental Ethics Education (EEE) deals with the education of ethical issues concerning the environment. A look into the environmental ethics of the employees shows that they believe in their responsibility to take care of the environment, the biodiversity, and the biosphere, and can be enhanced by future environmental ethics education training and by drafting and designing university policies which put ethics in consideration. The goals of EEE go beyond understanding nature and that everything is interconnected. EEE together with REB can develop positive attitudes and behavior towards the environment as well as develop a love of nature, promoting friendly life styles to the natural environment and to other living beings. Within a year after the conduct of the study, the use of Styrofoam as food containers had been banned inside the university. 


\section{Works Cited}

Aruna, Sivakami. "Can Education in Environmental Ethics Alone Solve Problems of Loss of Biodiversity in Developing Countries?” Asia-Pacific Perspectives on Environmental Ethics. Bangkok: UNESCO Bangkok, 2008. 47-52.

Asian Development Bank. The Garbage Book: Solid Waste Management in Metro Manila. 2004.

Asian Development Bank. The Garbage Book: Cost of Solid Waste. 2000.

Barnes, David, Galgani Francois, Thompson Richard, and Barlaz Morton. "Accumulation and Fragmentation of Plastic Debris in Global Environments.” Phil. Trans. R. Soc. B (2010) 364, 1985-1998. Doi: 10.1098/rstb.2008.0205.

Chawla, Louise. "Significant Life Experiences Revisited: A Review of Research as Sources of Environmental Sensitivity." The Journal of Environmental Education 20.3 (1998): 11-21.

Culen, Gerald, Hungerford Harold, Tomera Audrey, Sivek Daniel, Harrington Michael, and Michael Squillo. "A Comparison of Environmental Perceptions and Behaviors of 5 Discrete Populations.” The Journal of Environmental Education 17.2 (1986): 24-32.

Des Jardins, Joseph R. "Ethics, Public Policy, and Global Warming.” Applied Ethics: A Reader. Eds. Earl Winkler and Jerrold Coombs. Oxford and Cambridge: Blackwell Publishers, 2001. 313-28.

Environmental Education Guide. Department of Education, Culture and Sports, Department of Environment and Natural Resources-Environmental Management Bureau, Asian Development Bank, Colombo Plan Staff College for Technician Education, and Madecor Environmental Management Systems, Inc. 1999.

Geller, Jack and Paul Lansley. “The New Environmental Paradigm Scale: A Reexamination.” The Journal of Environmental Education 17.1 (1986/1987): 9-12.

Gleim, Joseph and Gleim Rosemary. "Calculating, Reporting and Interpreting Cronbach Alpha Reliability Coefficient for Likert-type Scales.” Midwest Research to Practice Conference in Adult, Continuing, Community Education, 2003.

Hart, Earl Paul. "Identification of Key Characteristics of Environmental Education.” The Journal of Environmental Education 13.1 (1981): 12-16.

Hines, Jody, Hungerford Harold, and Tomera Audrey. “Analysis and Synthesis of Responsible Environmental Behavior: A Meta-analysis.” The Journal of Environmental Education 18.2 (1986/1987): 1-8.

Hopewell, Jefferson, Dvorak Robert, and Kosior Edward. "Plastics Recycling: Challenges and Opportunities.” Philosophical Transactions of the Royal Society B 364 (2009): 2115-26.

Hungerford, Harold and Peyton Ben. Teaching Environmental Education. Portland: J. Weston Welch, 1976.

Hungerford, Harold, Peyton Ben, and Wilke Richard. "Goals for Curriculum Development in Environmental Education.” The Journal of Environmental Education 11.3 (1980): 42-47.

Jaus, Harold. “The Development and Retention of Environmental Attitudes in Elementary School Children.” The Journal of Environmental Education 15.3 (1984): 33-36.

Maloney, Michael and Michael Ward. "Ecology: Let’s Hear from the People: An Objective Scale for the Measurement of Ecological Attitudes and Knowledge.” American Psychologist 28.7 (1973): 583-6.

Marcinkowski, Stanley. “An Analysis of Correlates and Predictors of Responsible Environmental Behavior.” Doctoral dissertation, Southern Illinois University, Carbondale, 1988. Dissertation Abstracts International 49 (12A): 3677.

Nollen, Stanley and Karen Gaertner. "Effect of Skill and Attitude on Employee Performance and Earnings.” Industrial Relations 30.31 (1991): 344-455.

Paehlke, Robert. Conservation and Environmentalism: An Encyclopedia. London and Chicago: Fritzroy Dearborn Publishers, 1995.

Parayno, Phares and Mitzi Gay. Busmente Integration of Solid Waste Management Tools in Specific European and Asian Communities (ISTEAC). Paper Recycling Schemes in the Philippines.

Parfitt, Barthel and Macnaughton. "Food Waste within Food Supply Chains: Quantification and Potential for Change to 2050." Phil. Trans. R. Soc. B 365 (2010): 3065-81. Doi:10.1098/rstb.2010.0126. Accessed August 20, 2011.

Penrod, Steve. Social Psychology. 2nd ed. New Jersey: Prentice Hall, 1986.

Philippines $\quad$ Environmental Monitor, $2001 . \quad$ World <http://www.worldbank.org.ph/WBSITE/EXTERNAL/COUNTRIES/EASTASIAPACIFICEXT/PHILIPPINESEXTN/0,,con tentMDK:20544920 pagePK:141137 piPK:141127 theSitePK:332982,00.html>. Accessed October 15, 2010.

Peterson, N. "Developmental Variables Affecting Environmental Sensitivity in Professional Environmental Educators." Unpublished master’s thesis, Southern Illinos University Carbondale, 1982. 
The Philippines Brown Environment Report (September 2005). Report from the National Solid Waste Management Commission. Rao, Vijayendra and Reddy Remata. Environmental Education. New Delhi: Commonwealth Publishers, 1997.

Rigg, Jonathan (ed.). Counting the Costs: Economic Growth and Environmental Change in Thailand. Singapore: Institute of Southeast Asian Studies, 1995.

Segovia, Victoria and Galang Angelina. "Sustainable Development in Higher Education in the Philippines: The Case of Miriam College.” Higher Education Policy 15 (2002): 187-95.

Sia, Archibald, Hungerford Harold, and Tomera Audrey. "Selected Predictors of Responsible Environmental Behavior.” The Journal of Environmental Education 17.2 (1985/1986): 31-40.

Suliana, Siwatibau. "Ethical Dimensions for Sustaining Our Environment: A Pacific Island Perspective." Asia-Pacific Perspectives on Environmental Ethics. Bangkok: UNESCO Bangkok, 2008. 1-6.

Thompson, Richard, Moore Charles, Frederick vom Saal, and Shanna Swan. "Plastics, the Environment and Human Health: Current Consensus and Future Trends.” Phil. Trans. R. Soc. 364 (2009): 2153-66. Doi: 10.1098/rstb.2009.0053.

Thompson, Richard, Swan Shanna, Moore Charles, and Frederick vom Saal. “Our Plastic Age.” Phil. Trans. R. Soc. B 364 (2009): 1973-6. Doi: 10.1098/rstb.2009.0054.

Vinai, Veeravatnanond. “Environmental Education.” Bangkok: O.S. Printing House, 2003. 21-28.

Wongchantra Prayoon, Pairoj Boujai, Winyoo Sata, and Prasat Neungchalem. "Development of Environmental Education Teaching Process by Using Ethics Infusion for Undergraduate Students.” Pakistan Journal of Social Sciences 5.9 (2008): 941-4.

Yeong-Hyeon Hwang, Seong-Il Kim, and Jiann-Min Jeng. "Examining the Causal Relationships among Selected Antecedents of Responsible Environmental Behavior.” The Journal of Environmental Education 31.4 (2000): 19-25.

$<$ http://www.upd.edu.ph/ ovcca/about.html $>$. Accessed October 25, 2010.

<http://www.bioethics.gr/media/pdf/biolaw/other/UNESCO_Bioethics_Declaration.pdf >. Accessed October 25, 2010. 